\title{
A Study on the Baoxiang Flower Pattern in the Decorative Art of Tibetan Carpets
}

\author{
Li Wang ${ }^{1, *}$ \\ ${ }^{1}$ College of Art and Design, Wuhan Textile University, Wuhan, Hubei 430073, China \\ *Corresponding author. Email: 1320863179@qq.com
}

\begin{abstract}
Baoxiang flower pattern is a pattern with a long history and wide application in Tibetan carpet decoration art. It is the product of the combination of various flowers and symbolic meanings in nature. While focusing on practicality and aesthetics, it has a deep artistic origin with the Buddhism and Central Plains and other cultures behind it. This article explores the origins of Tibetan carpets and Baoxiang flower pattern, analyzes the pattern composition of the precious-phase patterns on Tibetan carpets, and interprets the aesthetic cultural connotations expressed by the patterns, hoping to provide reference for the inheritance and development of traditional Chinese patterns.
\end{abstract}

\section{Keywords: Tibetan carpets, Baoxiang flower, Buddhism, multiculturalism}

\section{INTRODUCTION}

Among the traditional handicrafts, Tibetan carpets have a long history. They are called "Wool Mats" by the archaeological community and are known as one of the three largest handmade carpets in the world. They occupy an important position in China and the world. The Tibetan ancestors initially simply wove wool into carpets, tapestries and other practical products to resist the cold. Later, they gradually gave them decorative meaning and artistic aesthetics, forming various styles of decorative art. For example, Qinghai Tibetan carpets are known as "Xining Great White Wool". They have unique weaving methods, bright colors and generous colors. The carpets have a soft texture and unique characteristics of toughness and wear resistance. With their strong national artistic patterns, they are appreciated and collected by the world. In the art history of Tibetan carpet decoration patterns, there is an ancient decorative pattern - Baoxiang flower. Its high degree of attention is a unique cultural phenomenon that is rare in other regions. It is not only a widely used decorative pattern in Tibetan carpets, but also has a deep relationship with Buddhism.

\section{THE ARTISTIC ORIGIN OF TIBETAN}

\section{CARPETS AND BAOXIANG FLOWER PATTERN}

\section{A. Origin of Baoxiang flower pattern}

The words "仙 xian" and "宝 bao" with special meanings are all related to Baoxiang flowers. Because of their particularity, the pattern rooted in Buddhist art. It was gradually brought into the Central Plains by Buddhism during the Wei, Jin and Southern and
Northern Dynasties. During the Sui and Tang Dynasties, it was praised and applied by dignitaries and became one of traditional Chinese decorative patterns. The term "Baoxiang" is mentioned in the Buddhist literature "Toutuo Temple Inscriptions", which describes the compassion, dignity and dignity of the Buddha, and is respected by the majority of Buddhist believers as the "Baoxiang", that is, "the solemn Baoxiang." Baoxiang flower is an abstract artificially conceived by transforming the special parts and symbolic meanings of various types of flowers in nature, and finally forming the main body with lotus and peony as the center, and the surrounding decorations with honeysuckle and curling grass patterns as supplements. The flower shape does not really exist in nature. Since ancient times, the lotus has a mythological color, and it is praised by scholars and writers for its characteristics of being out of silt and not muddy. Its flower shape is soft and perfect, the flower color is elegant, and it has noble quality, which is the same as the Buddhist philosophy. Buddhism requires people to be like lotus flowers, free from evil spirits in the muddy world. As the so-called "flowers bloom to see Buddha nature", lotus nature is Buddha nature, and it is holy, auspicious, and a symbol of pure land. All things related to Buddhism are decorated with lotus patterns, such as a Buddha holding a lotus in his hand or stepping on a lotus with his feet. In addition, on the walls, divine accounts, algae wells, sachets and other Buddhist objects, various lotus patterns are commonly carved and painted. If there is a lotus, there is a Buddha. The lotus is a symbol of the Buddha. This is full of strong religious implications. Because of the introduction of Buddhism, the decorative patterns of 
Tibetan carpets have undergone tremendous changes, integrating Buddhism, Tibetanism, and Chinese culture.

\section{B. The origin of Tibetan carpets and Baoxiang flower}

In the middle of the 7 th century, during the rule of Srongtsen Gampo, King of Tubo, the political situation was stable, the regional economy was prosperous, and the exchanges with the Central Plains and neighboring countries were gradually close, and cultural exchanges were frequent. Therefore, Buddhism was introduced into Tibet from China's Central Plains and South Asia. In the long-term development process, the local Bon religion and other places adapted to the cultural development and integration, and eventually formed Tibetan Buddhism. Admired by the ruling class, it had an important influence on social life, culture and art at that time. People built tall and magnificent temples such as the Jokhang Temple, which attracted thousands of Buddhist followers. Traditional Tibetan carpets have been influenced by Buddhism. In order to meet the needs of social development, they have absorbed various cultural elements such as Central Plains culture and South Asian culture, and produced the most representative Baoxiang flower pattern decoration in Tibetan carpets. In fact, the earliest Baoxiang flower pattern originated from the white water lily in the Nile River in India. It implies regeneration, meaning life and the sun. In ancient India, it was a token and symbol of the king. Later, it was brought into China by Buddhism, which enriched the connotation of the simple plant patterns before the Wei and Jin Dynasties. In the Tang Dynasty, the Baoxiang flower pattern not only combined the western lotus pattern and honeysuckle pattern, but also merged and transformed the local advocating and beloved peony pattern, which was magnificent and brilliant. Therefore, the Baoxiang flower pattern decoration in the Tibetan carpets has been influenced by multiple cultures, which not only satisfies the daily life of the nobles and the religious etiquette of the temple, but also forms a decorative style that adapts to the modeling style of the tower temple and the Tibetan belief and customs. This kind of Baoxiang flower pattern, mainly composed of lotus patterns, is widely used in the decoration of different parts of Tibetan carpets. It has different forms and diverse styles. It is the most common decorative pattern in Tibetan carpets. Whether it is the exquisite Tibetan carpets in the temples or the living objects of the Tibetan people, they hide the admiration and worship of Buddhism. It can be said that the Tibetan carpets are the materialization of Tibetan Buddhist thought, and theBaoxiang flower pattern on the Tibetan carpets is the carrier of religion. A Tibetan blanket not only carries the Tibetan people's pious practice and hopes to reach a lotus-like state, but also embodies the rich cultural heritage of the Chinese nation.

\section{THE PATTERN COMPOSITION OF THE BAOXIANG FLOWER PATTERN IN THE TIBETAN CARPETS}

Tibetan handicrafts combine art with national beliefs in decorative patterns, which makes up for the monotony of traditional Tibetan carpets. There are as many as several types of patterns in the form of Baoxiang flower pattern. From the perspective of composition form, they are divided into separate and continuous patterns. The single-patterned Baoxiang flower pattern is simple and atmospheric, with strong independence and subjectivity; the continuouspatterned Baoxiang flower pattern is full and gorgeous, giving people a visual feast. From the perspective of color application, it can be divided into religious and civil use. Tibetan carpets that reflect religious meaning are mostly used in temples and other solemn places. The main colors are blue, white, yellow, green, and red, which are simple and solemn. The meaning of each color is also very sophisticated. Civilian blankets pay more attention to practicality and daily life, and use bright colors in patterns, full of secular vitality.

\section{A. Single-patterned Baoxiang flower pattern}

In the Tibetan carpets, the single-patterned Baoxiang flower pattern decorations have a simple and elegant overall composition. The structure of the Baoxiang flower is symmetrical and uniform with the characters "+" and "米". The constituent elements are relatively simple. For example, the main position of the carpet often appears in the form of separate flowers such as lotus flowers and group flowers as the center, diverging to the surroundings, with fret patterns, honeysuckle patterns, and geometric patterns as a background. Not only the theme is obvious on the overall decoration screen, but the composition is also distinct. Generally speaking, in addition to floral decorations such as Baoxiang flower pattern, the individual patterns arranged on Tibetan carpets also have rich Buddhist content such as dragon patterns, vajra, Buddha, and eight auspicious colors. The colors are mainly blue, white, yellow, green and red. Legend has it that when Shakyamuni was enlightened, the Holy Body gave out these five colors of light. Among them, the most elegant is yellow and red, and yellow is also gold. For example, the top of the temple is a golden roof, the Buddha is sculptured as a golden body, and the monk master wears a yellow coat. In the eyes of Buddhists, it represents the sacred color of respect. Red is also an indispensable color in Buddhism. Zen masters often use cinnabar to copy scriptures or scripts written with blood as ink, which are full of respect for Buddhism. Therefore, the single-patterned Baoxiang flower pattern Tibetan carpets with separate patterns are mostly used in temples. The Baoxiang flower in the middle of the Tibetan carpets is plump, with symmetrical structure, simple form and elegant color. 
The warm yellow and cool blue are contrasted in color, conveying thought and emotion. The surrounding frame is decorated with square geometric patterns, and the vajra pestle is slightly embellished on the outer circle (see "Fig. 1"). The full and round figurative Baoxiang flower pattern and the square and orderly abstract vajra create a strong contrast effect, making the picture very decorative and balanced. Handicraftsmen often use contrasting techniques. The contrasts of large and small, curved and straight, cold and warm, concrete and abstract patterns and colors appear on the Tibetan carpets, which complement each other and present a peaceful scene. A typical Baoxiang flower pattern on the Tibetan carpet, looking down from the front, is like a lotus in full bloom, with symbolic Buddhist patterns,and full of religious majesty and mystery.

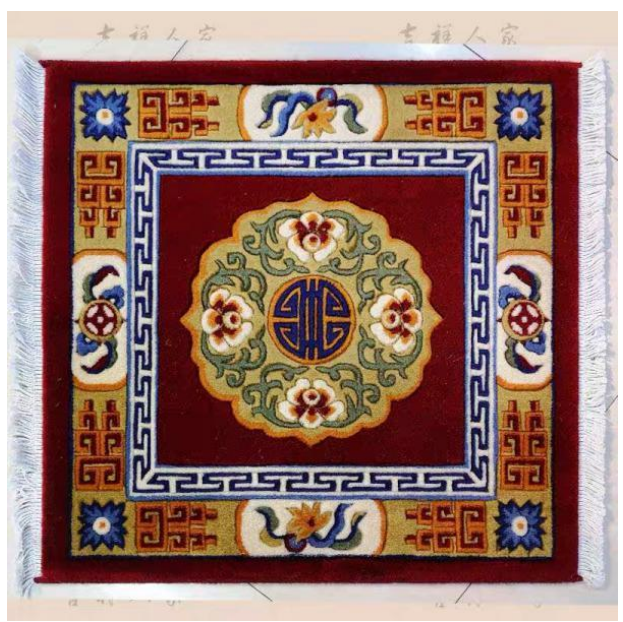

Fig. 1. Vajra cross pestle pattern.

\section{B. Continuous-patterned Baoxiang flower pattern}

There are continuous patterns of Baoxiang flower pattern decorations in the Tibetan carpets, and the pattern composition is mainly composed of multiple elements, such as peony pattern, curly grass pattern, twisted branch pattern, and eight treasures pattern. The continuous pattern is composed of one element repeatedly arranged and divided into two continuous or four continuous expansions. The two continuous patterns are mostly continuous up and down or left and right. They are generally located at the edge of the Tibetan carpets to play the main role of decoration, such as curly grass pattern, cloud pattern, etc. The tetragonal continuum is composed of one or several patterns forming a unit pattern, which is repeatedly extended and expanded around, forming a kind of decoration pattern that can be used to decorate the edge of the carpet, and can also be directly used as the main decorative pattern of the carpet, such as Baoxiang flower, round "福", round "寿", etc. The continuous pattern of the Baoxiang flower pattern in the Tibetan carpets, the overall composition is full and gorgeous, and the color is gorgeous and not vulgar. Different from the rigorous and solemn temple carpets, brightly colored floral patterns are incorporated here, as well as Buddhist symbols and Central Plains silk patterns. There are also unique patterns such as dragon and phoenix patterns, tiger skin patterns, and flower patterns used by nobles. At the same time, various colors such as camel, light blue, coral red are added, showing a sense of uniform order and harmony. The decorative patterns of Baoxiang flower on the Tibetan carpets are cleverly conceived, but they give a sense of regular order and a uniform layout. The form and content are ever-changing, and the colors are bold and natural, so they are mostly civilian carpets. Taking the pattern of the Baoxiang flower and the twisting branches as a unit, the patterns spread out front and back, using a large area of bright red as the base, and the elegant and fresh light blue Baoxiang flower and the twisting branches as the theme, arranged according to the law, complex and not messy. The most notable feature is that it can be repeated endlessly, extending continuously, forming a complex and changeable visual experience ("Fig. 2"). The Baoxiang flower pattern in these Tibetan carpets is integrated with many decorative colors. They have both the holy Buddhist lotus element and the characteristics of traditional Chinese patterns. It can also be seen from this that Tibetans are pursuing a secular vision of a better life while advocating the holy and untainted Buddhism.

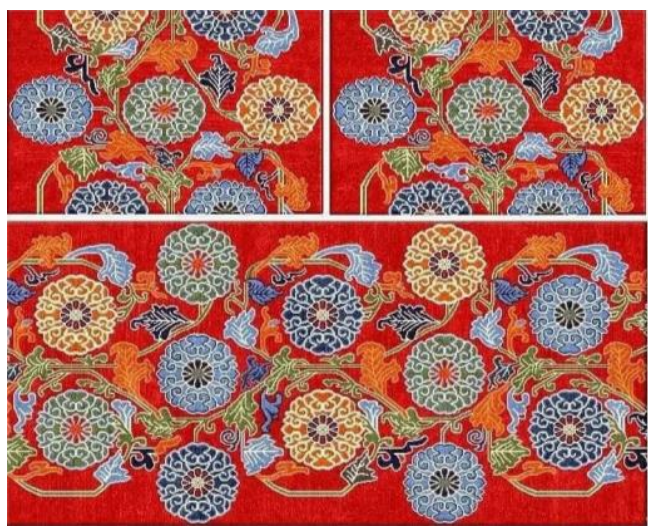

Fig. 2. Tibetan handicraft carpet.

\section{THE AESTHETIC CULTURAL CONNOTATION OF THE BAOXIANG FLOWER IN THE TIBETAN CARPETS}

With the introduction of Buddhism, the Baoxiang flower pattern in the Tibetan carpets is constantly updated and expanded with the development of time. The aesthetic and cultural connotations behind each pattern are the result of the historical accumulation of this nation. In the hearts of Tibetans, the Baoxiang flower pattern is endowed with an auspicious and complete national concept, and it is also a metaphor for 
the cycle of life in Buddhist thought. At the same time, the rich pattern forms and eclectic tolerance characteristics of Baoxiang flower pattern precisely reflect the warm and hospitable Tibetan people's acceptance and absorption of foreign cultures while continuing the essence of local culture.

\section{A. Metaphors of Buddhist thought}

The decorative patterns on Tibetan carpets generally have unique symbolic meanings. For example, the "dragon pattern" represents the emperor's rights, the "phoenix pattern" represents the queen, the homonym of bats and deer means happiness and fortune, etc. After a long period of Buddhist culture, the culture has gradually become deeply ingrained in Tibetan people's thinking. The Baoxiang flower pattern in the Tibetan carpets is round and plump, like the sun with huge energy, and also follows the Buddhist artistic concept of roundness as beauty, so they have auspicious meanings such as "consummation" and "being accommodating". The morphological characteristics of the Baoxiang flower pattern are also regarded by Tibetans as the golden wheel treasures in Buddhism. Tibetans call it "Koluo", which symbolizes the completeness of Buddhism. It rotates endlessly like a wheel and never goes out. In Tibetan Buddhism, the circle is the infinite reincarnation thought of life after the world's enlightenment to Buddhism, hoping to eradicate all suffering and reach the other side of wisdom and enlightenment. The beautiful expectations of the Tibetan people can be seen from these themes, and the Baoxiang flower pattern is the concrete carrier of the concept of auspiciousness, and it also greatly enhances the connotation of Tibetan Buddhism. Therefore, whether it is in the temples or on the Tibetan carpets in herdsmen's homes, people can see so many round ornaments such as Baoxiang flower, round " 寿", round dragon, round phoenix, etc., which all reflect the Tibetan people's desire to live a happy and fulfilling life. Therefore, the Baoxiang flower pattern on the Tibetan carpet not only conveys the noble and holy religious meaning of Buddhism, but also expresses the secular desire of the Tibetan people to express good luck.

\section{B. Multicultural integration}

After historical baptism and continuous enrichment, the decorative patterns in Tibetan carpets have long left a deep cultural imprint in the hearts of the Tibetan people, showing a "diversified" artistic feature. The diversification of Baoxiang flower pattern decoration can become one of the aesthetic characteristics of Tibetan carpets, and it is also the result of its willingness to abandon the same pattern and integrate various foreign cultures. Tibetan craftsmen use artistic techniques to imagine natural flowers and combine with the different characteristics of various ethnic groups and cultures to derive more perfect and typical artworks, which will give viewers the enjoyment of beauty. Thus, through the diversified treasure-like patterns on the Tibetan carpet, people can comprehend the craftsmanship of the wisdom of Tibetan craftsmen. Tibetan culture is gradually formed in the harsh snowcovered culture. The geographical location is far away but it adheres to an open and inclusive attitude, retains the essence of local culture, absorbs and draws on foreign cultures, and continuously improves and perfects Tibetan culture. It can be said that Tibetan culture is the final product of the fusion of multiple cultures, which can be clearly seen from the development of Tibetan carpets and decorative patterns. Grand Master Hsing Yun said in "Says": "Tolerance is emptiness, emptiness can contain everything, good and bad, no matter good or bad, it must be tolerant, just like the sea can accommodate hundreds of rivers." As an outstanding representative of Tibetan culture, Tibetan carpets show the tolerant and eclectic characteristics of this nation. They are deeply baptized by Buddhist culture and fully demonstrate that culture is not only national but also global. Persian carpets are well-known in China and foreign countries, and their decorative pattern art is similar to Tibetan carpets in some respects. If the two exchanges and learn from each other, will they burst out more splendid artistic sparks? The development of traditional culture has always been an issue worth thinking about.

\section{CONCLUSION}

To sum up, the dazzling Baoxiang flower pattern decoration art on Tibetan carpets originated from Buddhist culture, combining local culture and Central Plains culture. It is the Tibetan people's most pious belief in Buddhist culture, and it also embodies excellent multiculturalism. Its unique Baoxiang flower pattern decorations mainly composed of lotus flowers, honeysuckle pattern and entangled branch pattern as supplementary patterns. Its single patterns and continuous patterns are simple, pure, dignified and gorgeous, and are loved and widely used by the Tibetan people. It also reflects the psychological state of the Tibetan people in pursuit of Buddhism and a better life. With the advancing of time, the Baoxiang flower pattern decorations on the Tibetan carpets are constantly updated and expanded. Behind the decorations are rich Buddhist thoughts and cultures. For example, Baoxiang flower has a complete auspicious meaning and a symbol of the reincarnation of life. In addition to its strong religious color, it also expresses the secular wish of good luck. The emergence of the diversification of Baoxiang flower pattern decoration has benefited from the Tibetan people's pursuit of Buddhism to embrace all things in the world, and the formation of an open and inclusive character to the world. Not only has it promotes the socio-economic and 
cultural improvement, but also the lifestyle and living conditions in Tibet have been greatly improved. Nowadays, Baoxiang flower pattern decoration still occupies an important position in Tibetan carpets. It's just that when more and more modern new patterns are gradually pouring into the market, with rich styles and fashionable styles, it is very important whether the Tibetan carpet industry will retain the essence of traditional culture. Therefore, it is necessary to correctly respond to the rise of multiculturalism and make reasonable improvements, such as improving backward production tools, adjusting too strong religious significance, and adjusting to modern life patterns and daily needs. When thinking about innovation, it is also necessary to always maintain respect and awe for traditional Tibetan culture, start from the historical context, and not discard its unique aesthetic art, which will play an important role in guiding the future development of Tibetan carpets, and make it follow the sustainable development of culture. The Baoxiang flower pattern on the Tibetan carpets is dignified and magnificent. Its unique decorative beauty is a typical symbol of ethnic communication, integration, harmony and unity, and it should be inherited and developed.

\section{References}

[1] Zhuge Kai, The Influence of Buddhist Art on Chinese Flower Decoration [J]. National Arts, 2004. (in Chinese)

[2] Gao Ming, Happy Flower Patterns in Dunhuang Frescoes of Tang Dynasty [J]. Art \& Design, 2004 (11). (in Chinese)

[3] Su Bai, Archaeological Studies on Monasteries of the Tibetan Buddhism [M]. Beijing: Cultural Relics Publishing House, 1996: 156. (in Chinese)

[4] Zheng Jun, The Decorative art of Chinese Treasures [M]. People's Fine Arts Publishing House, 2008: 139. (in Chinese)

[5] Lei Guiyuan, Chinese and Foreign Pattern Decoration Style [M]. Beijing: People's Fine Arts Publishing House, 1985: 7. (in Chinese)

[6] Zhai Tian, Historical Evolution and Structural Analysis of Baoxiang Flower Pattern [D]. Xi'an Polytechnic University, 2014. (in Chinese)

[7] Xu Cui, Study on Artistic Symbols of Baoxiang Flower in Tang Dynasty [D]. Hunan University of Technology, 2009. (in Chinese)

[8] Lv Cheng, A Brief Introduction to the Origin of Chinese Buddhism [M]. Zhonghua Book Company, 1979. (in Chinese)

[9] Li Jing, Wang Hong, etc. Baoxiang Flower Pattern Set [M]. Tianjin: Tianjin People's Publishing House, 1996. (in Chinese)

[10] Ni Jianlin, Chinese Buddhist Decoration [M]. Nanning: Guangxi Fine Arts Publishing House, 2000. (in Chinese) 